\title{
DETERMINATION OF THE AGE AND GROWTH OF GLOSSOGOBIUS GIURIS (HAMILTON-BUCHANAN, 1822) USING SECTIONED OTOLITH
}

\author{
Md. Sagir Ahmed* and Gulshan Ara Latifa \\ Department of Zoology, University of Dhaka, Dhaka 1000, Bangladesh
}

\begin{abstract}
The freshwater gobi, Glossogobius giuris (Hamilton-Buchanan, 1822) (Gobiidae: Perciformes) is an important freshwater fish species in Bangladesh. The age and growth of this species, collected from the river Titas, Brahmanbaria, were studied with transverse sections of otoliths. The otolith's opaque zones that are formed every year were the annual rings. The growth of this species was rapid during the first two years, reaching $18.5 \mathrm{~cm}$ in total length. Most of the specimens were 1-2 years old and accounted for $90 \%$ in total. The maximum age recorded was five years with $19.5 \mathrm{~cm}$ in total length. The von Bertalanffy growth parameters $L_{\infty}$ and $K$ for this species were $19.58 \mathrm{~cm}$ and $1.36 /$ year, respectively. The study indicated that the age and growth of $G$. giuris can be determined using its sectioned otolith.
\end{abstract}

Key words: Glossogobius giuris, otolith, age and growth.

\section{INTRODUCTION}

The freshwater fish Glossogobius giuris (Hamilton-Buchanan, 1822) (Gobiidae: Perciformes) is widely distributed in the ponds, rivers and estuaries of Bangladesh, and forms an important capture fishery throughout the country. $G$. giuris is commonly called gobi and locally known as bele. It is a predatory fish and habitually preying upon the desirable species of fish at different stages of their rearing.

G. giuris is preferred by the people of Bangladesh as a delicious fish. This fish is also preferred in dry condition by the people especially in the coastal districts. To meet the rapidly increasing demand, large quantities of this fish are being caught every year without considering its stock.

Otoliths (earstones) are paired calcified structures used for balance and/or hearing in all teleost fishes. The fish otolith has long been known as a timekeeper. The use of otoliths as indicators of fish age has now reached the century landmark, starting with Reibisch's observations of otolith annuli in 1899. More importantly, for fisheries scientists and resource managers, otoliths are natural data loggers that record information in their microstructure chemistry at different temporal scales related to their growth and environment (Kalish 1989, Campana 1999). This information includes age and growth, movement patterns and habitat interactions.

*Corresponding author: E-mail: sagir_udhaka@hotmail.com 
In modern fishery, investigation on the determination of the age of fish occupies a very important place, since the knowledge of the ageing of fishes is of notable significance from both scientific and commercial point of view. The information on the correct age of fish are essential in solving life history problems as longevity, rates of growth, and age at maturity or spawning period (Rounsefell and Everhart 1953).

Few works that have been done on this species in Bangladesh are confined to the determination of length-weight relationship, biology and ecology (Islam 2004, Ahmed 2002, Doha 1974). So far, no attempt has yet been made to study the age and growth of this fish which is an essential prerequisite for understanding the population dynamics of this fish.

The objective of the study was to determine the age and growth of G. giuris with the expectation that information on such aspects of the biology of this fish would ultimately help in adopting proper management and conservation of this important fish.

\section{MATERIAL AND METHODS}

Sampling of fish: A total of 1837 specimens of G. giuris was sampled from the river Tias, Brahmanbaria from June 2006 to May 2007. Most specimens were caught with gill nets and long lines. The total length (TL) of each fish was recorded to the nearest $\mathrm{mm}$ from the tip of the snout to the tip of the caudal fin and weighed upto nearest gram using specific weight balances depending on the size of the fish. Only 54 specimens of different sizes were selected for otolith collection.

Collection and preparation of otolith: Otoliths were removed from the fish, washed with tap water, and then kept in dried condition. The right otoliths (sagittae) were used for age determination; the left sagittae were used if the right sagittae were damaged when extracted from the fish or during the sectioning process. The dried otoliths were then brought to the laboratory of Marine Biology and Oceanography, Faculty of Fisheries, Kagoshima University, Japan, for further processing. The length of otoliths was measured under a microscope (Olympus SZ-40, Japan) and weighed with a balance (Satorius 2462, Zeiss, Germany). Measured otoliths were embedded in epoxy resin, a mixture of Dodencenyl Succinic Anhydride (DDSA), Epok 812 (Epoxy equivalent 148), Methyl Mandic Anhydride (MNA), Dimethyl Aminomethyl Phenol (DPMP) (4.8:2.2:3.2). Embedded otoliths were cut with a microcutter (Model MC-201; Maruto Co., Ltd., Tokyo, Japan) and polished using a grinder (Model 9820; Makita Co., Ltd., Tokyo, Japan) in order to make transverse sections crossing 
the focus, leaving a thin slice of approximately $0.2 \mathrm{~mm}$ thick, and mounted on a glass slide and coated with nail enamel.

Reading of otoliths: The number of ring marks (outer edge of opaque zone) on the sectioned otoliths was counted using a microscope (LEICA MZ 12.5; Leica Microsystems, Heerbrugg, Switzerland) with transmitted light under a black background at 40x magnification. The annuli were counted by two readers and if there was an agreement between both readers, the resulting counts of the annuli was adopted. The ages were assigned to every individual according to the number of opaque zones observed in sectioned otolith.

Growth parameter: The monthly length frequency data of G. giuris were analyzed using FiSAT (FAO-ICLARM Stock Assessment Tools) as explained in details by Gayanilo et al. (1996). The fitting of the best von Bertalanffy growth curve was based on the ELEPHAN-I program (Pauly and David 1981), which allows the fitted curve through the maximum number of peaks of the frequency distribution. With the aid of the best growth curve, the growth constant $(K)$ and asymptotic length $\left(L_{\infty}\right)$ were estimated.

\section{RESULTS AND DISCUSSION}

Otolith description: The sagitta is laterally compressed. The distal surface is concave and the proximal surface is convex with a deep longitudinal groove known as sulcus acusticus. The dorsal margin is smooth and slightly tapering outwardly. The ventral margin is serrated. The rostrum is smaller and antirostrum is larger and they are separated by a small groove, excisural notch (Fig. 1). The posterior margin is rounded dorsally. The sulcus is homosulcoid and its opening is ostio-caudal type.

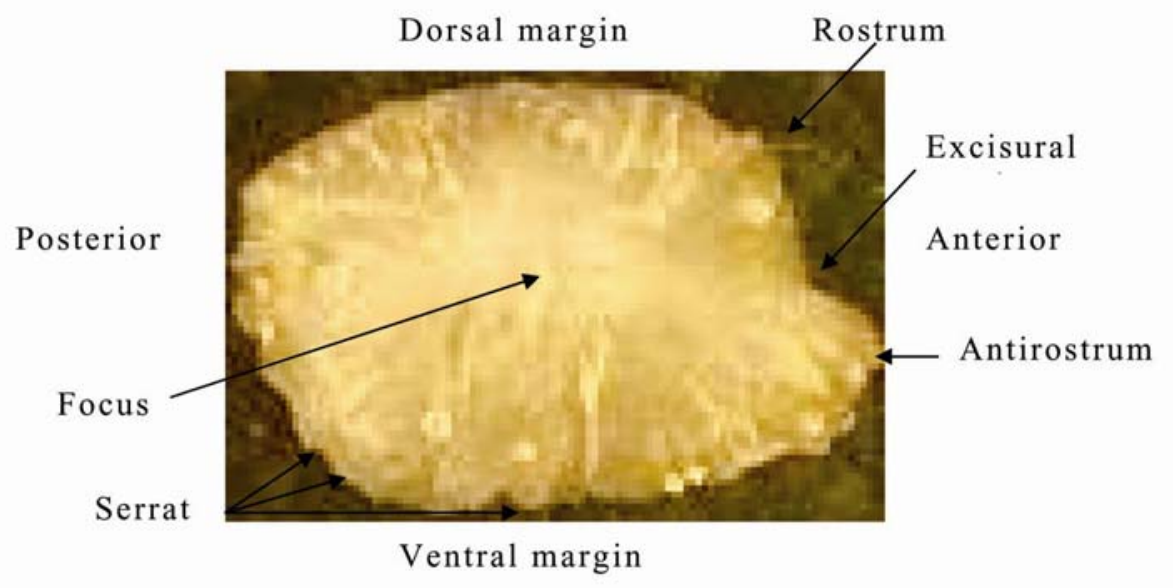

Fig. 1. Right otolith of Glossogobius giuris (lateral view). 
Age determination from otolith annuli: Otoliths, as well as other bony structures form yearly rings (similar to that of a tree) known as annuli. Each annulus is composed of opaque and translucent zones, which correspond to the periods of fast and slow growth. As the fish begins its life, it lays down daily rings as a result of an internal clock entrained by a 24-hour light and dark cycles. In addition environmental factors, such as feeding, activity and temperature variations, all contribute to the daily cycle (Campana and Neilson 1985). During the periods of slow growth, daily rings are formed extremely close together creating a thick band or annulus. In general, the opaque zone forms during the periods of increasing water temperatures, while a translucent zone is formed during the periods of reduced growth which may be associated with spawning.

The incidence of opaque and hyaline material at the margin of the otolith through an annual period suggests some degree of periodicity in the ring formation for G. giuris (Figs. 2, 3). In the otoliths the opaque rings were always broader suggesting that they equate with the fast growth or summer rings of shallow-water species (Fig. 3). On the assumption that the rings were laid down annually, age estimates ranged from one to five years for G. giuris. Ahmed et al. (2008) demonstrated that annual rings were formed in the otoliths of Tenualosa ilish and the age estimated ranged from one to six years for T. ilisha.

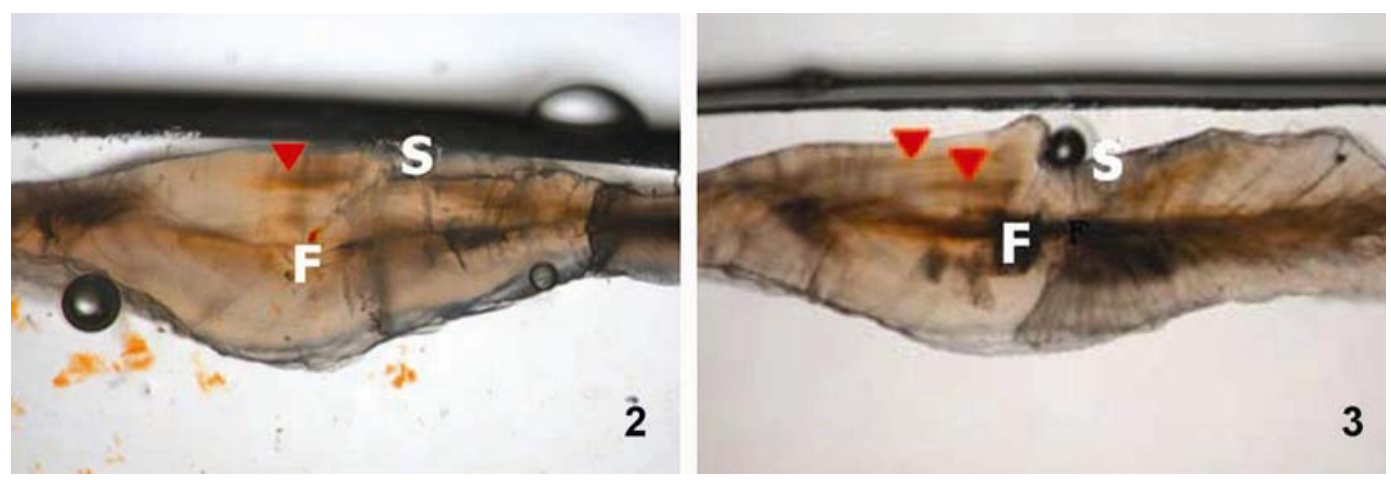

Figs. 2-3: 2. Sectioned otolith of Glossogobius giuris showing one year mark (annulus). $\mathrm{S}=\mathrm{Sulcus}, \mathrm{F}=$ Focus. 3. Sectioned otolith of Glossogobius giuris showing two-year marks (annuli). $\mathrm{S}=\mathrm{Sulcus,}$ $\mathrm{F}=$ Focus.

Otolith weight $v$ s fish length: The relationship between the total length and otolith length, and body weight and otolith weight were examined. It showed that there were strong positive relationship between total length and otolith length $\left(r^{2}=0.93\right)$ and total length and otolith weight $\left.r^{2}=0.86\right)$. The age-length keys rely on the relationship between age and fish length, an alternative approach is to take advantage of the well-documented proportionality between the size of the 
otolith and both the size and the age of the fish (Templeman and Squires 1956). Although the sizes of the fish and the otolith are correlated, otolith size tends to be somewhat more correlated with fish age than with fish length (Boehlert 1985). Thus, in principle, otolith size can better be used to infer fish age than fish length. A number of studies has statistically been related to various measurements of otolith size (e.g., otolith weight, length and area) to the annulus-based age and then used the resulting relationships to estimate the age composition of the remaining unaged fish (Boehlert 1985, Pawson 1990). A common feature shared by this approach and that of the age-length key is that both require two samples: "calibration" and "production". The calibration sample (sometimes called the training sample) is used to define a procedure for estimating age, and this procedure is then applied to all fish in the production sample (sometimes called the test sample).

Otolith weight could constitute a valid and simple method to estimate the age structure of a fish population (Fletcher 1991, 1995, Worthington et al. 1995a,b, Fletcher and Blight 1996). Data from this study showed that otolith weight, rather than fish length, was a better estimator of G. giuris age. These findings were in agreement with that shown by the weight technique which is strictly dependent on a correct age determination through the annuli counting of those individuals used in the calibration. The power of otolith weight to predict the age of G. giuris was higher for younger fish, decreasing with the increasing age of the fish. However, the otolith ageing obviously determines an increase in the power of otolith weight to estimate the fish age. The results of this study are promising, confirming that otolith weight can estimate the age with the same level of accuracy as that of annuli counting.

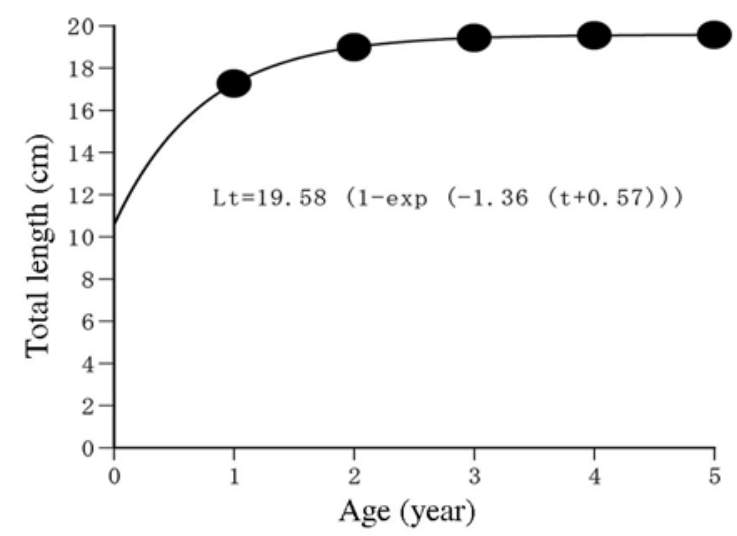

Fig. 4. von Bertalanffy growth curve of Glossogobius giuris ( $L_{\propto}=19.58 \mathrm{~cm}$ and $\mathrm{K}=1.36 /$ year). 
von Bertelanffy growth equation: The best fitted von Bertelanffy growth equation obtained was $\mathrm{TL}_{\mathrm{t}}=19.58(1-\exp (-1.36(\mathrm{t}+0.57)))$ for combined sexes, where $t$ is age (year) and $T L_{t}$ is the total length $(\mathrm{cm})$ at age $t$ and maximum age observed was approximately five years. It indicated that the growth is very rapid and it reaches maximum length within two years (Fig. 4 ).

Concluding remarks: Around the world, the ages of many fishes are determined each year using otoliths. Fish age is generally determined after initial preparation of the otolith (such as embedding and thin sectioning) followed by microscopic examination and counts of the annual growth zones (annuli). The preparation process is often time consuming, while the interpretation of the annuli requires skilled technicians. The present study demonstrates that year marks or annuli are formed in the otolith of G. giuris and age determination is possible through counting of the year marks.

Acknowledgements: The authors are grateful to Prof. Yasuji Masuda, Faculty of Fisheries, Kagoshima University, Japan, for his kind support in taking otoliths reading.

\section{LITERATURE CITED}

AHMED, M.S. 2002. The biological basis of fisheries management in the Floodplain River Titas, Brahmabaria. Project Report. SUFER Project, DFID, UGC. 110 pp.

AHMED, M.S., SHARIF, A.S.M. and LATIFA, G.A. 2008. Age growth and mortality of hilsa shad, Tenualosa ilisha in the River Meghna, Bangladesh. Asian j. Biol. Sci. 1(2): 69-76.

BOEHLERT, G.W. 1985. Using objective criteria and multiple regression models for age determination in fishes. Fish. Bull. 83: 103-117.

CAMPANA, S.E. 1999. Chemistry and composition of fish otoliths: pathways, mechanisms and applications. Marine Ecological Progress Series 188: 263-297.

CAMPANA, S.E. and NEILSON, J.D. 1985. Microstructure of fish otoliths. Can. J. Fish. Aquat. Sci. 42: 1014-1032.

DOHA, S. 1974. Investigation into the biology of the gobi, Glossogobius giuris (Hamilton-Buchanan). Bangladesh J. Zool. 2: 95-106.

FLETCHER, W.J. 1991. A test of the relationship between otolith weight and age for the pilchard Sardinops neopilchardus. Can. J. Fish. Aquat. Sci. 48: 35-38.

FLETCHER, W.J. 1995. An application of the age-otolith weight realtionship for the pilchard Sardinops sagax neopilchardus. Can. J. Fish. Aquat. Sci. 52: 657-664

FLETCHER, W.J. and BLIGHT, S.J. 1996. Validity of using translucent zones of otoliths to age the pilchard Sardinops sagax neopilchardus from Albany, Western Australia. Marine Freshwater Res. 47: 617-624.

GAYANILO, F.C., SPARRE, JR. P. and PAULY, D. 1996. FAO-ICLARM Stock Assessment Tools (FiSAT) user's Guide. FAO Computerized Information Series (Fisheries). No. 8. Rome, FAO, 266 pp.

ISLAM, M.N. 2004. Eco-biology of freshwater gobi, Glossogobious giuris (Hamilton) of the river Padma in relation to its fishery: A review. J. Biol. Sci. 4(6): 780-793.

KALISH, J.M. 1989. Otolith microchemistry: validation of the effects of physiology, age and environment on otolith composition. J. Experimental Marine Biology and Ecology 132: 151-178. 
PAULY, D. and DAVID, N. 1981. ELEFAN-I a basic program for the objective extraction of growth parameters from length frequency data. Meeresforschung/Rep.Mar. Res. 28(4):205-211.

PAWSON, M.G. 1990. Using otolith weight to age fish. J. Fish Biol. 36: 521531.

REIBISCH, J. 1899. U” ber die Eizahl bei Pleuronectes platessa und die Altersbestimmung dieser Form aus den Otolithen. Wissenschaftliche Meeresuntersuchungen 4: 232-248.

ROUNSFELL, G.A. and EVERHART, W.H. 1953. Fishery Science. John Wiley and Sons, Inc. 444 pp.

TEMPLEMAN, W. and SQUIRES, H.J. 1956. Relationship of otolith lengths and weights in the haddock Melanogrammus aeglefinus (L.) to the rate of growth of the fish. J. Fish. Res. Board Can. 13: 467-487.

WORTHINGTON, D.G., DOHERTY, P.J. and FOWLER, A.J. 1995a: Variation in the relationship between otolith weight and age: implications for the estimation of age of two tropical damsel-fish (Pomacentrus moluccensis and P. wardi). Can. J. Fish. Aquat. Sci. 52: 233-242.

WORTHINGTON, D.G., FOWLER, A.J. and DOHERTY, P.J. 1995b. Determining the most efficient method of age determination for estimating the age structure of a fish population. Can. J. Fish. Aquat. Sci. 52: 2320-2326. 